\title{
Overexpression of CD44 is associated with the occurrence and migration of non-small cell lung cancer
}

\author{
GUANGHU LI ${ }^{1}$, YUFEI GAO ${ }^{2}$, YONGSHENG CUI ${ }^{1}$, TAO ZHANG ${ }^{3}$, RUI CUI ${ }^{4}$, YANG JIANG ${ }^{5}$ and JINGWEI SHI \\ ${ }^{1}$ Department of Thoracic Surgery, The First Hospital of Jilin University, Changchun, Jilin 130021; \\ Departments of ${ }^{2}$ Neurosurgery, ${ }^{3}$ Gastrointestinal Surgery, ${ }^{4}$ Laboratory Medicine Center and ${ }^{5}$ Colorectal Surgery, \\ China-Japan Union Hospital, Jilin University, Changchun, Jilin 130033, P.R. China
}

Received May 15, 2015; Accepted July 7, 2016

DOI: $10.3892 / \mathrm{mmr} .2016 .5636$

\begin{abstract}
Non-small cell lung cancer (NSCLC) is a potentially fatal disease and the incidence is increasing annually. In order to diagnose and treat NSCLC effectively, greater understanding of its molecular mechanism is required. In the present study, 36 NSCLC tissues and 10 normal tissues were selected. Reverse transcription-quantitative polymerase chain reaction (RT-qPCR) was used to analyze the CD44 mRNA expression level in NSCLC tissue and DNA sequencing was performed to further verify the CD44 expression level. Differentially expressed genes between tumor tissues and controls were determined by DNA sequencing and the Gene_act_net between CD44 and its associated genes was constructed. Gene Ontology (GO) term enrichment analysis of the differentially expressed genes was performed by the Biological Networks Gene Ontology tool. Kyoto Encyclopedia of Genes and Genomes (KEGG) pathway enrichment analysis was performed based on the Expression Analysis Systematic Explorer test applied in the Database for Annotation, Visualization and Integrated Discovery. RT-qPCR results showed that CD34 was overexpressed in 21 of the 36 NSCLC tissues (58.3\%). The Gene_act_net indicated that there were 20 differentially expressed genes with 17 upregulated and 3 downregulated. Among them, CD44, MET, ERBB2, EGFR, AKT1, IQGAP1 and STAT3 were associated with the occurrence and migration of NSCLC. In KEGG pathway analysis, extracellular matrix-receptor interaction and hematopoietic
\end{abstract}

Correspondence to: Dr Jingwei Shi, Department of Laboratory Medicine Center, China-Japan Union Hospital, Jilin University, 126 Xiantai Street, Changchun, Jilin 130033, P.R. China

E-mail: shi123jingwei@163.com

Dr Yang Jiang, Department of Colorectal Surgery, China-Japan Union Hospital, Jilin University, 126 Xiantai Street, Changchun, Jilin 130033, P.R. China

E-mail: jy7555@163.com

Key words: non-small cell lung cancer, CD44, DNA sequencing, reverse transcription-quantitative polymerase chain reaction, Kyoto Encyclopedia of Genes and Genomes pathway cell lineage pathways were the most affected by overexpressed CD44; and thus may be important in the development and migration of NSCLC. In conclusion, CD44 was overexpressed in NSCLC and the overexpression was associated with the occurrence of NSCLC and migration of NSCLC cells.

\section{Introduction}

Primary lung cancer is the most common type of malignancy after non-melanocytic skin cancer, and the leading cause of human cancer-related fatality worldwide (1). While it has been the most important cause of cancer-related mortality in men since the 1960s, it and breast cancer have been identified as the most important causes of mortality in women (2). Lung cancer is increasing in prevalence and mortality rates worldwide (3). In developed countries, the latter has begun to decline in men, reflecting a decrease in smoking, and is reaching a plateau for women in the majority of European countries and in the United States, where lung cancer mortality rates in women are approaching those in men (4). Lung cancer fatalities in women were expected to increase (+7\%) in the EU in 2012 (5). Non-small cell lung cancer (NSCLC) accounts for $80-85 \%$ of all lung cancer cases (6). The management of NSCLC requires a multidisciplinary approach. Patients generally require a combination of surgery, radiotherapy and/or chemotherapy, depending on the stage, resectability and overall performance status (7). Chemotherapy is now recognized as an important component in the treatment of all stages of the disease, including in patients with completely resected, early stage disease, who benefit with improved survival rates when adjuvant platinum-based chemotherapy is administered (8). However, the majority of patients are not diagnosed until the disease has spread beyond the primary tumor site. Moreover, the occurrence rate is increasing annually (9). Therefore, there is a high unmet need for innovative approaches to prevent the occurrence and migration of NSCLC.

CD44 is a $90-\mathrm{kDa}$ transmembrane glycoprotein that is widely distributed on the surface of $\mathrm{T}$ cells, granulocytes, monocytes, fibroblasts, keratinocytes and epithelial cells, and is involved in various cell adhesion events, including lymphocyte migration, hematopoiesis and tumor metastasis (10). It is expressed on cell surfaces in several isoforms, which are generated by alternative splicing of mRNA (11). Expression of 
CD44 and its variants has been shown to be associated with tumor progression in various types of human malignancy (12). CD44 is a broadly distributed cell surface protein hypothesized to mediate cell attachment to extracellular matrix components or specific cell surface ligands (13). The CD44 family of surface receptors regulates adhesion, movement and activation of normal and neoplastic cells (14). A previous study demonstrated that the expression of the CD44 variant exon 6 is associated with lymph node metastasis in NSCLC (15). Furthermore, standard and variant CD44 isoforms are commonly expressed in lung cancer of the non-small cell type but not of the small cell type (16). In addition, CD44 stimulation is known to downregulate Fas expression and Fas-mediated apoptosis of lung cancer cells (17). CD44 standard and CD44 variant 6 levels in patients with NSCLC were not significantly different from those in patients with benign lung disease $(18,19)$.

To the best of our knowledge, no studies have been conducted regarding the significance of CD44 expression with outcome and migration of NSCLC. In order to explore the significance of CD44 expression in human NSCLC, the expression pattern of CD44 was investigated using reverse transcription-quantitative polymerase chain reaction (RT-qPCR) and DNA sequencing. Followed by Gene Ontology (GO) term and Kyoto Encyclopedia of Genes and Genomes (KEGG) pathway enrichment analysis.

\section{Materials and methods}

Patients and samples. NSCLC tissue wax block samples of 36 cases were obtained from the Department of Thoracic Surgery in the First Hospital of Jilin University (Changchun, China) between January 2002 and July 2003. The samples were obtained from 28 men and 8 women, with a mean age of 63.5 years (range, $43-73$ years). Normal lung tissues $(5 \mathrm{~cm}$ away from the cancer tissue) of 10 cases were taken as negative controls. The present study was approved by the First Hospital of Jilin University and written informed consent was obtained from the patients.

$R T-q P C R$. RNA was extracted from tumor and normal tissues using the Agilent Technologies Total RNA Isolation Mini kit (Agilent Technologies, Palo Alto, CA, USA) according to the manufacturer's protocol. Spectrophotometric methods were used to assess the quality and quantity of the RNA samples. Reverse transcription was performed using $1 \mu \mathrm{g}$ of total RNA and the Advantage RT-for-PCR kit (Takara Bio, Inc., Otsu, Japan) according to the manufacturer's instructions. Conventional PCR primers were designed to allow amplification of regions that have no overlap with other known genes and span at least one intron. The following primers were synthesized by BioAsia (Hyderabad, India): Forward: 5'-ACAACT GGTGATGGAGACTCATCC-3' and reverse: 5'-GATTCC AGAGTGGCTTATCATCTTGG-3' for CD44; and forward 5'-TGGAATCCTGTGGCATCCATGAAAC-3' and reverse 5'-TAAAACGCAGCTCAGTAACAGTCCG-3' for glyceraldehyde 2-phosphate dehydrogenase (GAPDH). Conventional PCR was performed using cDNA from tissues together with the Real-time qPCR Master mix-SYBR Advantage qPCR Premix (Takara Bio, Inc.) using respective primers in a
PTC-100 thermocycler (Bio-Rad Laboratories, Inc., Hercules, CA, USA). The reaction conditions were as follows: $95^{\circ} \mathrm{C}$ for $5 \mathrm{~min}, 94^{\circ} \mathrm{C}$ for $1 \mathrm{~min}, 55^{\circ} \mathrm{C}$ for $45 \mathrm{sec}, 72^{\circ} \mathrm{C}$ for $30 \mathrm{sec}$ and a final extension phase at $72^{\circ} \mathrm{C}$ for $7 \mathrm{~min}$ for 40 cycles. The PCR products were separated on a $2 \%$ agarose gel and stained with $5 \mu \mathrm{l}$ ethidium bromide prior to examination under UV light and images were captured (GIS-700D digital imaging analysis system; Shanghai Tianneng Electronics Co., Ltd., Shanghai, China). Fluorescence data was collected at the extension step using a UV-254 ultraviolet transmission and reflection analyzer (Beijing Dingguo Changsheng Biotechnology, Co., Ltd., Beijing, China). The relative expression of the target gene was determined using the $2^{-\Delta \Delta \mathrm{Cq}}$ method (20). Optical density was analyzed by Imagemaster VDS (Amersham Biosciences, Freiburg, Germany) image analysis software. The CD44 mRNA expression level was expressed as the CD44/ $\beta$-actin optical density ratio. CD44: $\beta$-actin $>0.5$ was considered to indicate positive expression.

DNA sequencing. The DNA sequence represents a single format onto which a broad range of biological phenomena can be projected for high-throughput data collection (21). Tumor and normal tissues were digested with appropriate volume of phosphate-buffered saline (PBS) and proteinase K. Then DNA was extracted by saturated phenol and the mixed liquor of phenol, chloroform and isoamylol. The extracted DNA was precipitated with absolute ethyl alcohol, washed with $70 \%$ ethanol and dissolved in cell lysis buffer after drying. Primers were designed and synthesized by the method reported by Guldberg et al (22) and the sequences were as follows: 5'-ACA ACTGGTGATGGAGACTCATCC-3' and 5'-GATTCCAGAGTGGCTTATCATCTTGG-3'. PCR was conducted using an ABI GeneAmp 2700 Mastercycler Personal (Applied Biosystems, Stockholm, Sweden). The total volume of the PCR reaction system was $25 \mu 1$, containing $1 \mu \mathrm{l}$ template DNA, $0.25 \mathrm{mmol} / \mathrm{l} \mathrm{dNTP}, 0.25 \mu \mathrm{l}$ Taq DNA polymerase, $0.8 \mu \mathrm{mol} / 1$ primer and $2.5 \mathrm{mmol} / \mathrm{Mg}^{2+}$. The reaction conditions were as follows: Initial denaturation was performed at $94^{\circ} \mathrm{C}$ for $5 \mathrm{~min}, 94^{\circ} \mathrm{C}$ for $30 \mathrm{sec}, 52^{\circ} \mathrm{C}$ for $30 \mathrm{sec}$, $72^{\circ} \mathrm{C}$ for $60 \mathrm{sec}$ for $40 \mathrm{cycles}$, and a final extension phase at $72^{\circ} \mathrm{C}$ for $10 \mathrm{~min}$. The PCR products of $10 \mu \mathrm{l}$ were selected for electrophoresis on a $2 \%$ agarose gel. Electrophoresis products were recycled and purified. DNA sequencing was performed by the 310 style DNA sequencer (Applied Biosystems, Foster City, CA, USA). The results were analyzed with DNASIS MAX V 3.0 software (MiraiBio; Hitachi Corporation, Tokyo, Japan).

Functional enrichment analysis and pathway enrichment analysis. In order to facilitate the functional analysis of the large lists of genes in the results, the Biological Networks Gene Ontology tool (BiNGO, plugin of Cytoscape) for GO term enrichment analysis was used (23). GO is a controlled vocabulary that is structured as a directed acyclic graph, and describes genes and their products (hereafter referred to simply as 'genes') in any organism (23). Genes from a number of organisms have been annotated to GO terms. A widespread application is the identification of annotation-enriched GO terms in a list of genes that share biological characteristics, the so-called study set compared with a larger list of genes, 


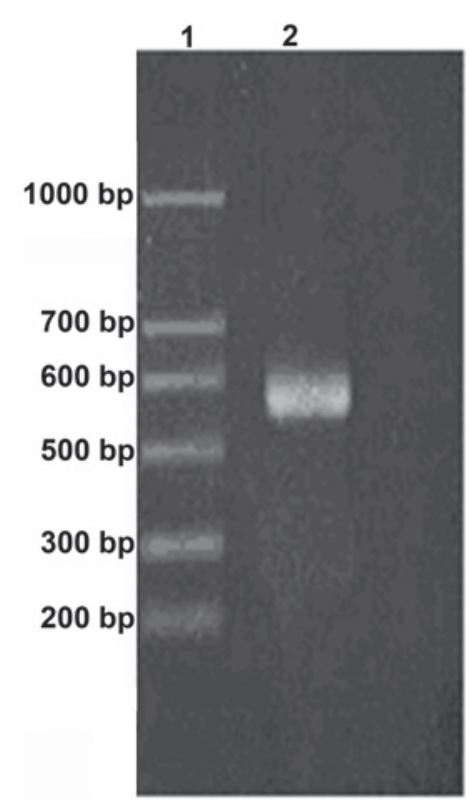

Figure 1. CD44 expression in the 10 normal tissues following amplification by reverse transcription-polymerase chain reaction. Lane 1, DL1000 DNA Ladder Marker; lane 2, CD44 gene.

the population set. These terms are often interpreted as representing the salient biological features of the genes in the study set (24). The false discovery rate is determined. It is a statistical approach used in multiple hypothesis testing to correct for multiple comparisons. It is typically used in highthroughput experiments in order to correct for random events that falsely appear significant (25).

KEGG is a knowledge base for systematic analysis of gene functions, linking genomic information with higher order functional information (26). KEGG pathway enrichment analysis was conducted with $\mathrm{P}<0.01$ based on Expression Analysis Systematic Explorer (EASE) test applied in The Database for Annotation, Visualization and Integrated Discovery (27). The EASE score was used to detect the significant categories. The threshold of EASE score $<0.01$ was considered significant for a category. The principle of EASE is shown in the following equation:

$$
p=\frac{\left(\begin{array}{c}
a+b \\
a
\end{array}\right)\left(\begin{array}{c}
c+d \\
c
\end{array}\right)}{\left(\begin{array}{c}
n \\
a+c
\end{array}\right)}
$$

Where $\mathrm{n}$ is the number of background genes; $\mathrm{a}^{\prime}$ is the gene number of one gene set in the gene lists; $a^{\prime}+b$ is the number of genes in the gene list including at least one gene set; $a^{\prime}+c$ is the gene number of one gene list in the background genes; $a^{\prime}$ is replaced with $\mathrm{a}=\mathrm{a}-1$.

Statistical analysis. Differences within groups in all assays were tested by analysis of variance and Dunnett's test. $\mathrm{P}<0.05$ was considered to indicate a statistically significant difference. Statistical analysis was implemented by SPSS 19.0 software (SPSS Inc., Chicago, IL, USA). All experiments were repeated three times.

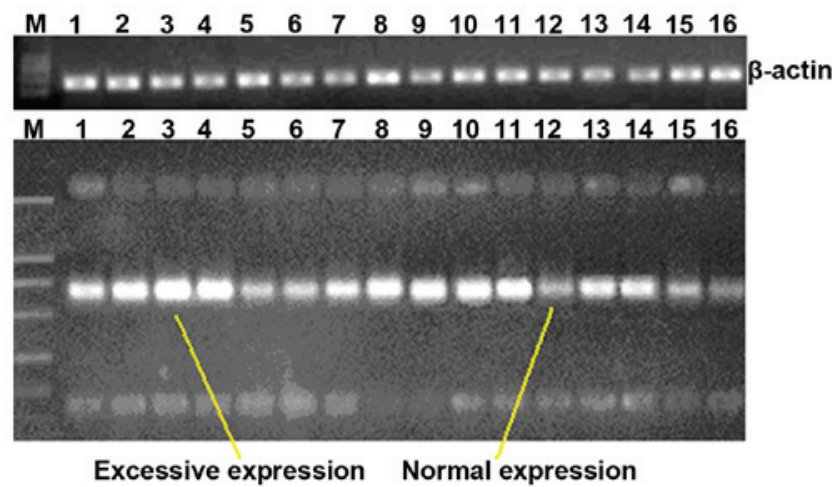

Figure 2. CD44 expression of the 36 cases of NSCLC after amplification by reverse transcription-quantitative polymerase chain reaction. $\mathrm{M}$, marker; Lanes 1, 2, 3, 4, 7, 8, 9, 10,11, 13 and 14, overexpression; and lanes 5, 6, 12, 15 and 16 , normal expression.

\section{Results}

$R T$-qPCR. RT-qPCR was used to determine CD44 mRNA expression in NSCLC and the normal tissue. The electrophoresis results were recorded by a gel scanning imaging system. Optical density values were analyzed by Imagemaster VDS image analysis software. The CD44 mRNA expression level was determined by the CD $44 / \beta$-actin optical density ratio. CD $44 / \beta$-actin $>0.5$ was considered to indicate positive expression. CD44 expression occurred in AGAR condensed electrophoresis after 10 cases of the normal tissues was amplified by RT-PCR and the result is shown in Fig. 1. Representative CD44 expression is indicated in lane 2, compared to the DNA ladder. In the same conditions, CD34 was overexpressed in 21 of the 36 cases NSCLC tissues and the overexpression rate was $58.3 \%$ (Fig. 2).

DNA sequencing. In order to further demonstrate that CD34 was overexpressed, DNA sequencing was used to analyze the CD34 expression conditions in NSCLC and normal tissues. The sequencing results underwent bioinformatics analysis. In total, 1,375 genes were found to be differentially expressed between the NSCLC and normal tissues. Among them, 136 genes were downregulated and 1,239 genes were upregulated. CD44 and all related genes were used to construct Gene_act_net (Fig. 3). As shown, 20 genes were differentially expressed. Among them, 17 genes were upregulated (MET, ERBB2, EGFR, ITPR3, ARHGEF1, RHOA, JUN, ACTG1, ITGA3, AKT1, ACTB, IQGAP1, ITGA9, ITGB6, STAT3, DDX5 and CD44) and three genes were downregulated (COL6A3, LAMB1 and COL1A1).

GO enrichment analysis. The results of GO enrichment analysis of the differentially expressed genes are shown in Fig. 4. GO enrichment analysis of total genes, upregulated genes and downregulated genes is shown in Fig. 4A-C, respectively. From the results, it was demonstrated that the following pathways in the biological process GO term $(\mathrm{P}<0.05)$ : Respiratory electron transport chain (5.27E-08), cellular metabolic process (1.40E-07), mitochondrial electron transport, NADH to ubiquinone (1.16E-06), SRP-dependent cotranslational protein targeting to membrane (2.64E-42), translational initiation (5.2E-41) and viral transcription (5.08E-40). The cellular 


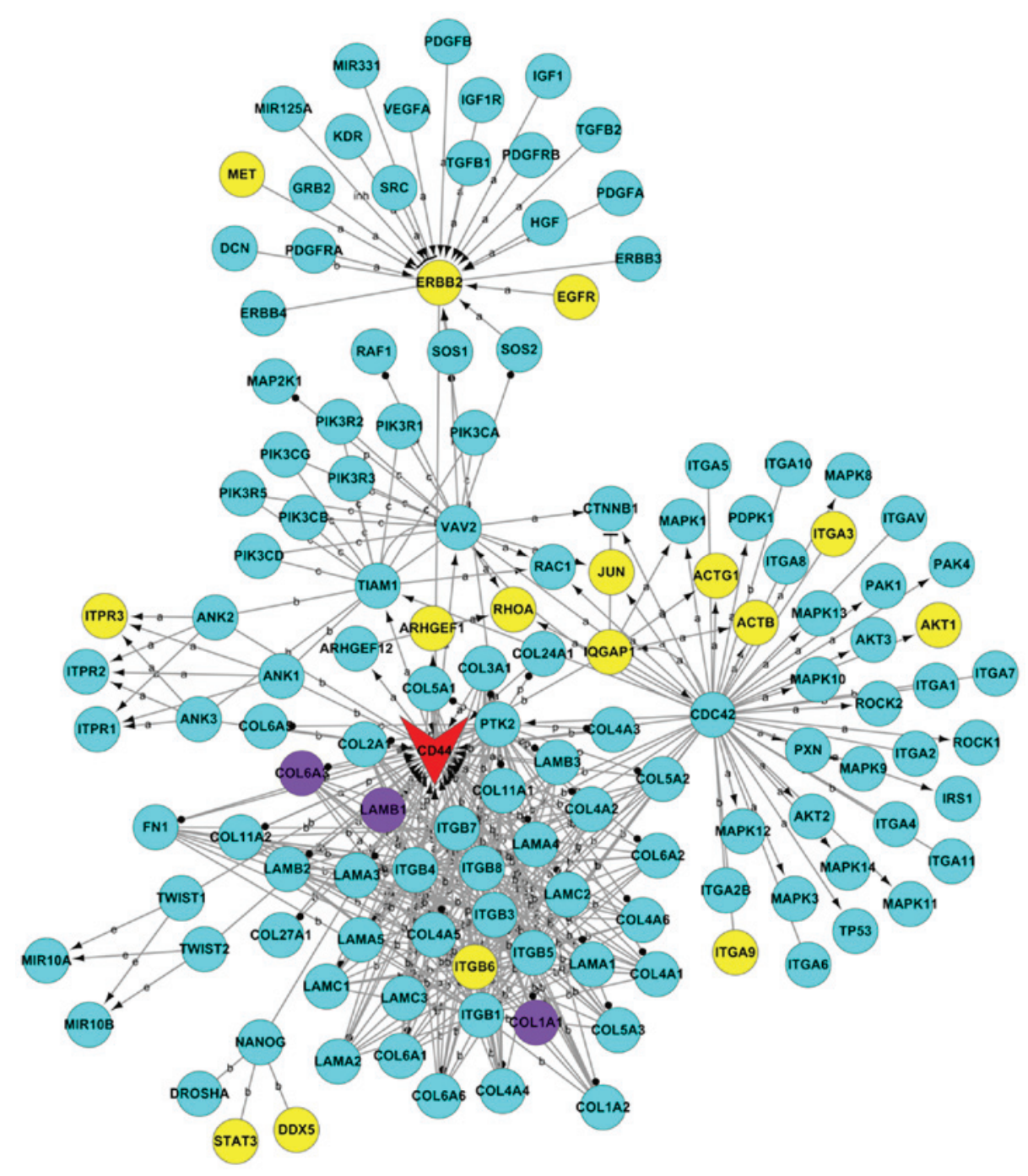

Figure 3. Gene_act_net between CD44 and its related genes. Purple represents the downregulated genes, yellow represents the upregulated genes, sky blue represents no differential expression.

component $\mathrm{GO}$ term $(\mathrm{P}<0.05)$ was associated with respiratory chain (4.11E-07), mitochondrial respiratory chain complex I (1.39E-06), mitochondrial inner membrane (6.94E-05), ribonucleoprotein complex (1.33E-34), ribosome (1.99E-29) and cytosolic large ribosomal subunit (6.86E-25). Molecular function $\mathrm{GO}$ term $(\mathrm{P}<0.05)$ was associated with nicotinamide adenine dinucleotide (NADH) dehydrogenase (ubiquinone) activity (1.35E-06), prolactin receptor binding (0.0006), oxidoreductase activity (0.0011), structural constituent of ribosome (4.75E-29), RNA binding (8.7E-11) and protein binding (1.04E-10).

Pathway enrichment analysis. The EASE analysis method conducted in the present study included a number of factors including the statistical significance of the set of differentially expressed genes in the pathway, the topology of the signaling pathway and their interactions.

Pathway enrichment analysis of the differentially expressed genes yielded a number of significant pathways, the extracellular matrix-receptor interaction and hematopoietic cell lineage pathways were most affected by overexpression of CD44 and, thus, important in the development and migration of NSCLC. As shown in Fig. 5, differentially expressed genes CD44, SDC3, LAMB1, ITGA9, ITGA3, ITGB6, SDC4, COL1A1, HSPG2, SDC1 and COL6A3 were involved in the ECM-receptor interaction pathway. Differentially expressed genes CD44, CD9, HLA-DRB5, CSF1R, IL1R1, HLA-DRA, ITGA3, CD14, CD55, CD4, CD59 and HLA-DRB1 were involved in the hematopoietic cell lineage pathway.

\section{Discussion}

Lung cancer is the leading cause of cancer-related mortality worldwide and its prevalence and mortality is increasing. NSCLC accounts for $80-85 \%$ of lung cancers. Chemotherapy is now recognized as an important component of treatment for all stages of NSCLC. However, the majority of patients are not diagnosed until the disease has spread beyond the primary tumor site. Moreover, the occurrence rate is increasing annually. Therefore, greater understanding of NSCLC at the molecular level is required. Defining new molecular targets may aid the development of more effective therapeutic strategies. In the present study, RT-qPCR was used to investigate the expression level of CD44 mRNA and the result showed that CD44 


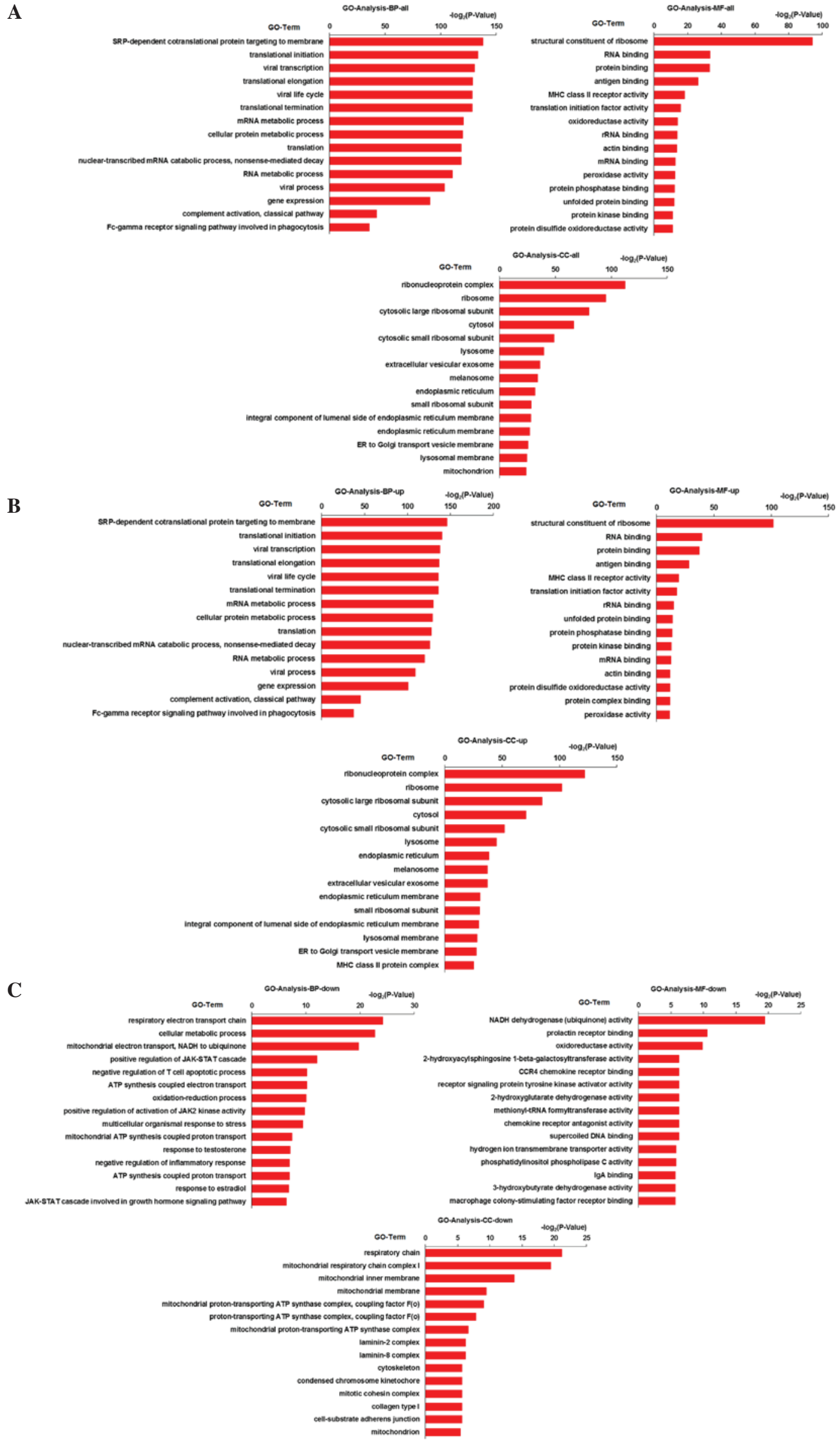

Figure 4. GO enrichment analysis results of the differentially expressed genes in NSCLC. (A) GO enrichment analysis result of all differential expressed genes. (B) GO enrichment analysis result of the upregulated genes. (C) GO enrichment analysis result of the downregulated genes. GO, gene ontology; NSCLC, non-small cell lung cancer. 
A

Pathway-Analysis

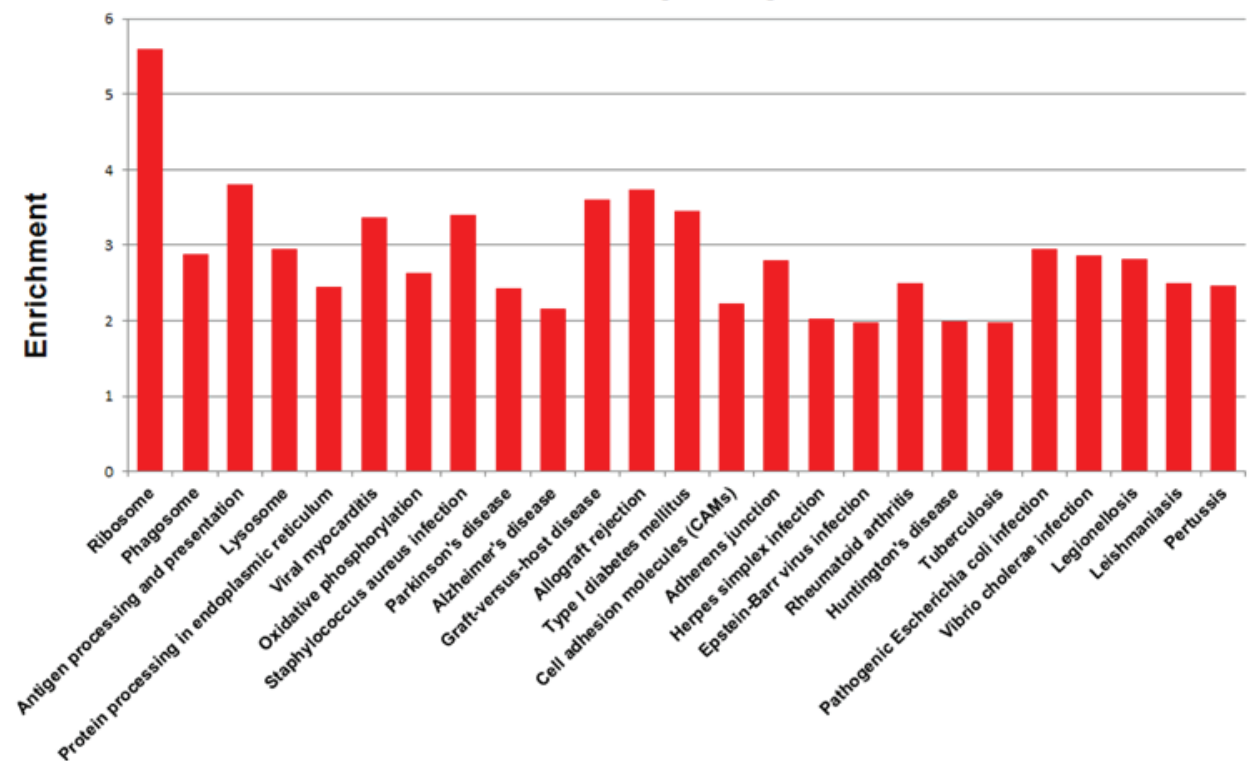

B

Pathway-Analysis

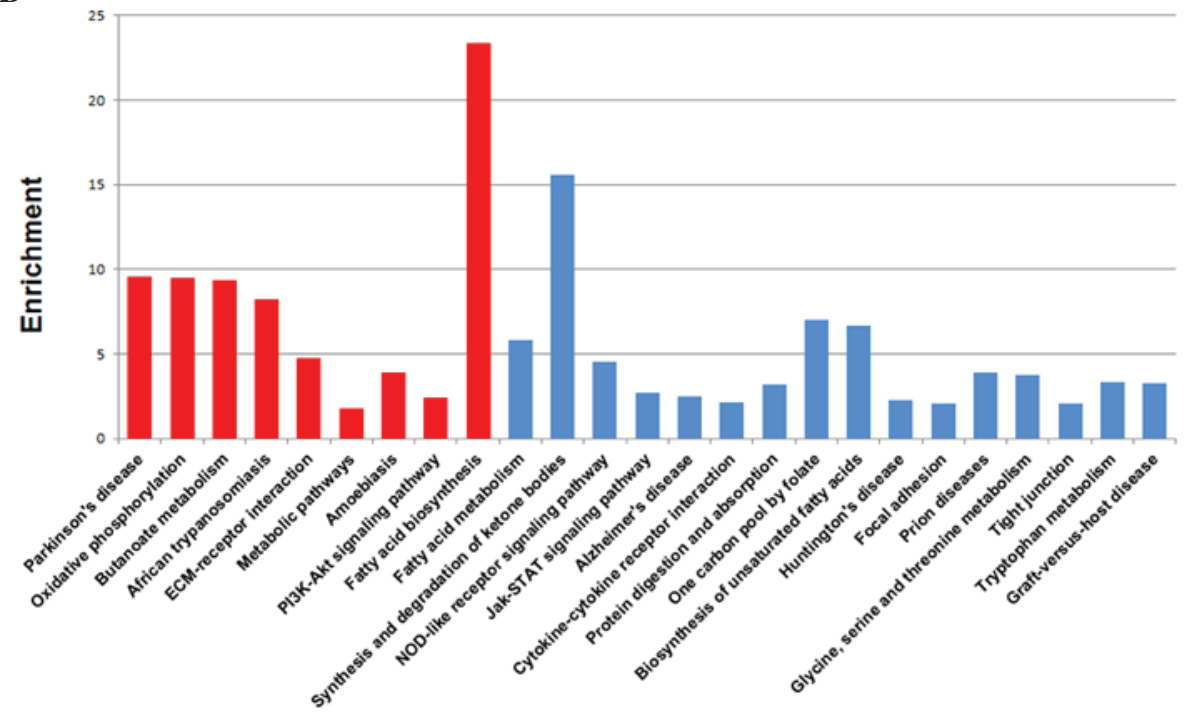

C

Pathway-Analysis

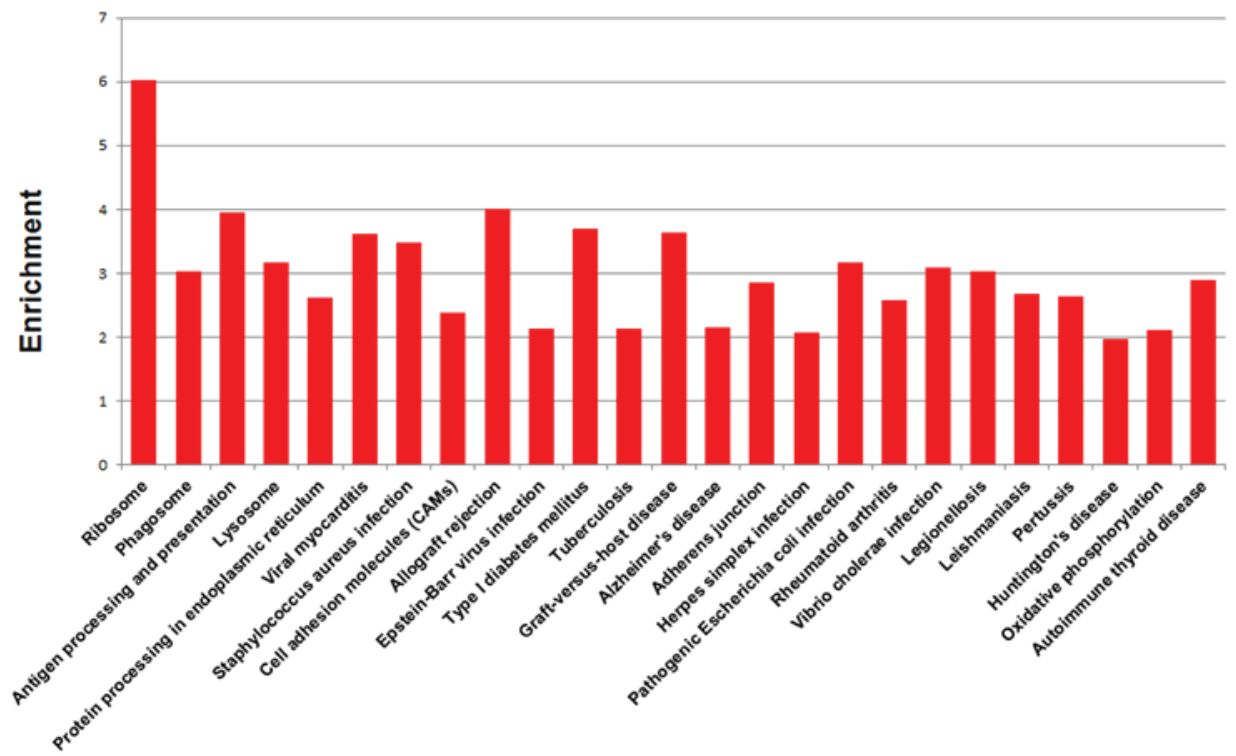

Figure 5. Pathway-Act-Net of the differentially expressed genes. (A) KEGG pathway of all differential expressed genes. (B) KEGG pathway of the upregulated genes. (C) KEGG pathway of the downregulated genes. KEGG, Kyoto Encyclopedia of Genes and Genomes pathway. 
mRNA was overexpressed. To further prove the overexpression of CD44, DNA sequencing was used to analyze the differentially expressed genes between NSCLC tissues and normal tissues. In total, 1,375 genes were found to be differentially expressed. Among them, 136 genes were downregulated and 1,239 genes, including CD44, were upregulated. CD44 and all the related genes were used to construct Gene_act_net. Among them, 17 genes were upregulated and 3 were downregulated. The 17 upregulated genes were MET, ERBB2, EGFR, ITPR3, ARHGEF1, RHOA, JUN, ACTG1, ITGA3, AKT1, ACTB, IQGAP1, ITGA9, ITGB6, STAT3, DDX5 and CD44. The 3 downregulated genes were: COL6A3, LAMB1 and COL1A1.

CD44 is a principle hyaluronate receptor and a transmembrane glycoprotein (28). It exists in a standard form (CD44s), and in multiple isoforms (29). It has been described as important in various aspects of cancer progression, including cell growth control, adhesion, migration and invasion $(30,31)$. A number of primary carcinoma tissues have been shown to express high levels of CD44 (32). Its expression was important for NSCLC COX-2-dependent invasion (33). Miyoshi et al (15) reported that in NSCLC, a number of variant forms of CD44 are frequently expressed and that the expression of CD44v6 is particularly associated with lymph node metastasis in NSCLC. Yasuda et al (17) found that CD44 was highly expressed on the surface of lung cancer cells and it stimulated the downregulation of Fas expression and Fas-mediated apoptosis of lung cancer cells. Therefore, it was concluded that CD44 was associated with the occurrence and migration of NSCLC.

MET amplification can activate ERBB3/PI3K/AKT signaling in EGFR mutant lung cancers and causes resistance to EGFR kinase inhibitors (34). MET amplification in NSCLC is likely a primary oncogenic driver and is a valid clinical target (35). MET has a prognostic role in surgically resected NSCLC, gene copy number increased by MET is an independent negative prognostic factor in surgically resected NSCLC (36). ERBB2 is a 185-Da transmembrane protein (p185 HER2) tyrosine kinase (37). Mutations in the ERBB2 gene were recently found in $\sim 2 \%$ of primary NSCLC specimens (38). Overexpression of the ERBB2 protein is observed in a variety of malignancies, including NSCLC (39). EGFR is critical in the control of cellular proliferation, differentiation and survival (40). Mutations of the EGFR gene have been identified in specimens from patients with non-small cell lung cancer respond to anilinoquinazoline EGFR inhibitors (41). EGF is a promising target for anticancer therapy as it is expressed or highly expressed in a variety of tumors, including NSCLC (42). AKT1, a downstream mediator of phosphatidylinositol 3-kinase (PI3K), is a signal transduction protein that is central in tumorigenesis (43). It has been implicated in lung tumorigenesis and lung cancer drug resistance, and can be activated in NSCLC $(44,45)$. IQGAP1 is a scaffold protein whose function is associated with signal transduction, cell adhesion, local invasion and distant metastasis of cancer cells (46). Downregulation of IQGAP1 can decrease proliferation, migration and invasion potential in NSCLC metastasis (47). Activation of STAT3 is important in tumorigenesis and tumor progression (48). The overexpression of STAT3 has been found in various malignancies, including NSCLC (49). Thus, studies have indicated that
MET, ERBB2, EGFR, AKT1, IQGAP1, STAT3 were associated with the occurrence and migration of NSCLC.

The KEGG pathway of the differentially expressed genes was investigated. ECM-receptor interaction and hematopoietic cell lineage pathways were affected by overexpressed CD44. The ECM-receptor interaction pathway involved CD44, SDC3, LAMB1, ITGA9, ITGA3, ITGB6, SDC4, COL1A1, HSPG2, SDC1 and COL6A3. ECM-receptor interactions have a profound influence on major cellular programs including growth, differentiation, migration and survival (50). Of the 11 genes, CD44, ITGA9, ITGA3 and COL1A1 were associated with NSCLC occurrence. ITGA9 was found to be downregulated in NSCLC and strongly inhibited colony formation in renal and lung cancer cell lines $(51,52)$. Fan et al $(53)$ performed analysis of expression of integrins in three different lung cancer cell lines, including A549 adenocarcinoma cells, H1650 bronchioalveolar carcinoma cells and DMS53 small cell carcinoma cells. Upregulated expression of ITGA4 was detectable in H1650 cells and ITGA3 was observed in all the lung cancer cells (53). High expression of COL1A1 was found in NSCLC (54). In addition, loss of expression of SDC1 is known to be associated with biologic aggressiveness and poor outcome for patients with NSCLC (55). The soluble SDC1 is associated with shorter survival in chronic lymphocytic leukemia and lung cancer (56). Overexpression of this enzyme appears to be crucial to promote tumor growth and metastasis in a number of types of cancer, including lung cancer (57). CD44, CD9, HLA-DRB5, CSF1R, IL1R1, HLA-DRA, ITGA3, CD14, CD55, CD4, CD59 and HLA-DRB1 were shown to be involved in the hematopoietic cell lineage pathway. CD44 was reported to be important in the occurrence and migration of NSCLC. CD9 is involved in Schwann cell migration in vitro (58) and is also downregulated in metastatic tumors (59). ITGA3 is an important integrin, and integrin $\alpha 3 / \beta 1$ was found to be expressed in $82 \%$ of metastatic tumors (60). It was reported to exhibit a role in MYC-induced liver cancer (61). CD14 is involved in hemorrhagic shock-induced alterations of the monocyte tumor necrosis factor response to endotoxin (62). CD55 is overexpressed in certain tumor cell lines, and in colorectal carcinomas, it has been shown to be an indicator of a poor prognosis (63). Therefore, it was concluded that ECM-receptor interaction and hematopoietic cell lineage pathway are key in the occurrence and migration of tumor.

Above all, it was concluded that CD44 was overexpressed in NSCLC and the overexpression was associated with the occurrence and migration of NSCLC. This may aid in the development of novel treatment strategies for NSCLC in the clinic.

\section{Acknowledgements}

The current study was supported by the Science and Technology Development Plan of Jilin Province (grant nos. 20110717 and 20140520019JH), the Key Scientific and Technological Projects of Jilin Province (grant no. 20150204026YY), the International Science and Technology Cooperation Project of Jilin Province (grant no. 20160414047GH), the Strategic Adjustment of Economic Structure Guiding Funds of Jilin Province (grant no. 2015Y032) and the Education Department of Jilin Province (grant no. 449). 


\section{References}

1. Jemal A, Bray F, Center MM, Ferlay J, Ward E and Forman D: Global cancer statistics. CA Cancer J Clin 61: 69-90, 2011.

2. Yang P, Allen MS, Aubry MC, Wampfler JA, Marks RS, Edell ES, Thibodeau S, Adjei AA, Jett J and Deschamps C: Clinical features of 5,628 primary lung cancer patients: Experience at Mayo clinic from 1997 to 2003. Chest 128: 452-462, 2005.

3. Pope CA III, Burnett RT, Thun MJ, Calle EE, Krewski D, Ito K and Thurston GD: Lung cancer, cardiopulmonary mortality, and long-term exposure to fine particulate air pollution. JAMA 287: 1132-1141, 2002.

4. Thatcher N, Chang A, Parikh P, Rodrigues Pereira J, Ciuleanu T, von Pawel J, Thongprasert S, Tan EH, Pemberton K, Archer V and Carroll K: Gefitinib plus best supportive care in previously treated patients with refractory advanced non-small-cell lung cancer: Results from a randomised, placebo-controlled, multicentre study (Iressa Survival Evaluation in Lung Cancer). Lancet 366: 1527-1537, 2005.

5. Malvezzi M, Bertuccio P, Levi F, La Vecchi C and Negri E: European cancer mortality predictions for the year 2012. Ann Oncol: mds024, 2012.

6. Graham MV, Purdy JA, Emami B, Harms W, Bosch W, Lockett MA and Perez CA: Clinical dose-volume histogram analysis for pneumonitis after 3D treatment for non-small cell lung cancer (NSCLC). Int J Radiat Oncol Biol Phys 45: 323-329, 1999.

7. Goldstraw P, Ball D, Jett JR, et al: Non-small-cell lung cancer. The Lancet 378: 1727-1740, 2011.

8. Früh M, Rolland E, Pignon JP, Seymour L, Ding K, Tribodet H, Winton T, Le Chevalier T, Scagliotti GV, Douillard JY, et al: Pooled analysis of the effect of age on adjuvant cisplatin-based chemotherapy for completely resected non-small-cell lung cancer. J Clin Oncol 26: 3573-3581, 2008.

9. Shepherd F, Pereira J, Ciuleanu T, et al: A randomized placebo-controlled trial of erlotinib in patients with advanced non-small cell lung cancer (NSCLC) following failure of 1st line or 2nd line chemotherapy. A National Cancer Institute of Canada Clinical Trials Group (NCIC CTG) trial. In: ASCO Annual Meeting Proceedings, $\mathrm{p}$ 7022, 2004.

10. Yasuda M, Nakano K, Yasumoto K and Tanaka Y: CD44: Functional relevance to inflammation and malignancy. Histol Histopathol 17: 945-950, 2002.

11. Mizera-Nyczak E, Dyszkiewicz W, Heider KH and Zeromski J: Isoform expression of CD44 adhesion molecules, Bcl-2, p53 and Ki-67 proteins in lung cancer. Tumour Biol 22: 45-53, 2001.

12. Situ D, Long H, Lin P, Zhu Z, Wang J, Zhang X, Xie Z and Rong T: Expression and prognostic relevance of CD44v6 in stage I non-small cell lung carcinoma. J Cancer Res Clin Oncol 136: 1213-1219, 2010

13. Aruffo A, Stamenkovic I, Melnick M, Underhill CB and Seed B: CD44 is the principal cell surface receptor for hyaluronate. cell 61: 1303-1313, 1990 .

14. Weber GF, Ashkar S, Glimcher MJ and Cantor $\mathrm{H}$ : Receptor-ligand interaction between CD44 and osteopontin (Eta-1). Science 271: 509-512, 1996.

15. Miyoshi T, Kondo K, Hino N, Uyama T and Monden Y: The expression of the CD44 variant exon 6 is associated with lymph node metastasis in non-small cell lung cancer. Clin Cancer Res 3: 1289-1297, 1997.

16. Ariza A, Mate JL, Isamat M,López D, Von Uexküll-Güldeband C, Rosell R, Fernández-Vasalo A and Navas-Palacios JJ: Standard and variant CD44 isoforms are commonly expressed in lung cancer of the non-small cell type but not of the small cell type. J Pathol 177: 363-368, 1995.

17. Yasuda M, Tanaka Y, Fujii K and Yasumoto K: CD44 stimulation down-regulates Fas expression and Fas-mediated apoptosis of lung cancer cells. Int Immunol 13: 1309-1319, 2001.

18. Takigawa N, Segawa Y, Mandai K, Takata I and Fujimoto N: Serum CD44 levels in patients with non-small cell lung cancer and their relationship with clinicopathological features. Lung Cancer 18: 147-157, 1997.

19. Szpechcinski A, Rudzinski P, Kupis W, Langfort R, Orlowski T and Chorostowska-Wynimko J: Plasma cell-free DNA levels and integrity in patients with chest radiological findings: NSCLC versus benign lung nodules. Cancer Lett 374: 202-207, 2016.

20. Livak KJ and Schmittgen TD: Analysis of relative gene expression data using real-time quantitative PCR and the 2 (-Delta Delta C(T)) method. Methods 25: 402-408, 2001.
21. Shendure J and Ji H: Next-generation DNA sequencing. Nat Biotechnol 26: 1135-1145, 2008.

22. Guldberg P, Romano V, Ceratto N, Bosco P, Ciuna M, Indelicato A, Mollica F, Meli C, Giovannini M and Riva E: Mutational spectrum of phenylalanine hydroxylase deficiency in sicily: Implications for diagnosis of hyperphenylalaninemia in southern Europe. Hum Mol Genet 2: 1703-1707, 1993.

23. Ashburner M, Ball CA, Blake JA, Botstein D, Butler H, Cherry JM, Davis AP, Dolinski K, Dwight SS, Eppig JT, et al: Gene ontology: Tool for the unification of biology. The Gene Ontology Consortium. Nat Genet 25: 25-29, 2000.

24. Bauer S, Grossmann S, Vingron M and Robinson PN: Ontologizer 2.0-a multifunctional tool for GO term enrichment analysis and data exploration. Bioinformatics 24: 1650-1651, 2008.

25. Wang J: Functional Enrichment Analysis. In: Encyclopedia of Systems Biology Springer, pp 772-772, 2013.

26. Kanehisa M and Goto S: KEGG: Kyoto encyclopedia of genes and genomes. Nucleic Acids Res 28: 27-30, 2000.

27. Hosack DA, Dennis G Jr, Sherman BT, Lane HC and Lempicki RA: Identifying biological themes within lists of genes with EASE. Genome Biol 4: R70, 2003.

28. Banerji S, Ni J, Wang SX, Clasper S, Su J, Tammi R, Jones M and Jackson DG: LYVE-1, a new homologue of the CD44 glycoprotein, is a lymph-specific receptor for hyaluronan. J Cell Biol 144: 789-801, 1999.

29. De la Torre M, Heldin P and Bergh J: Expression of the CD44 glycoprotein (lymphocyte-homing receptor) in untreated human breast cancer and its relationship to prognostic markers. Anticancer Res 15: 2791-2795, 1995.

30. Kito H, Suzuki H, Ichikawa T, Sekita N, Kamiya N, Akakura K, Igarashi T, Nakayama T, Watanabe M, Harigaya $\mathrm{K}$ and Ito $\mathrm{H}$ : Hypermethylation of the CD44 gene is associated with progression and metastasis of human prostate cancer. Prostate 49: 110-115, 2001.

31. Pinheiro C, Reis RM, Ricardo S, Longatto-Filho A, Schmitt F and Baltazar F: Expression of monocarboxylate transporters 1, 2 , and 4 in human tumours and their association with CD147 and CD44. J Biomed Biotechnol: 2010.

32. Stamenkovic I, Amiot M, Pesando JM and Seed B: A lymphocyte molecule implicated in lymph node homing is a member of the cartilage link protein family. Cell 56: 1057-1062, 1989.

33. Dohadwala M, Batra RK, Luo J, Lin Y, Krysan K, Pold M, Sharma S and Dubinett SM: Autocrine/paracrine prostaglandin E2 production by non-small cell lung cancer cells regulates matrix metalloproteinase-2 and CD44 in cyclooxygenase-2-dependent invasion. J Biol Chem 277: 50828-50833, 2002.

34. Turke AB, Zejnullahu K, Wu YL, Song Y, Dias-Santagata D, Lifshits E, Toschi L, Rogers A, Mok T, Sequist L, et al: Preexistence and clonal selection of MET amplification in EGFR mutant NSCLC. Cancer cell 17: 77-88, 2010.

35. Ou SH, Kwak EL, Siwak Tapp C, Dy J, Bergethon K, Clark JW, Camidge DR, Solomon BJ, Maki RG, Bang YJ, et al: Activity of crizotinib (PF02341066), a dual mesenchymal-epithelial transition (MET) and anaplastic lymphoma kinase (ALK) inhibitor, in a non-small cell lung cancer patient with de novo MET amplification. J Thorac Oncol 6: 942-946, 2011.

36. Cappuzzo F, Marchetti A, Skokan M, Rossi E, Gajapathy S, Felicioni L, Del Grammastro M, Sciarrotta MG, Buttitta F, Incarbone M, et al: Increased MET gene copy number negatively affects survival of surgically resected non-small-cell lung cancer patients. J Clin Oncol 27: 1667-1674, 2009.

37. Nakamura H, Saji H, Ogata A, Hosaka M, Hagiwara M, Kawasaki $\mathrm{N}$ and Kato $\mathrm{H}$ : Correlation between encoded protein overexpression and copy number of the HER2 gene with survival in non-small cell lung cancer. Int J Cancer 103: 61-66, 2003.

38. Minami Y, Shimamura T, Shah K, LaFramboise T, Glatt KA, Liniker E, Borgman CL, Haringsma HJ, Feng W, Weir BA, et al: The major lung cancer-derived mutants of ERBB2 are oncogenic and are associated with sensitivity to the irreversible EGFR/ERBB2 inhibitor HKI-272. Oncogene 26: 5023-5027, 2007.

39. Kristiansen G, Yu Y, Petersen S, Kaufmann O, Schlüns K, Dietel $\mathrm{M}$ and Petersen I: Overexpression of c-erbB2 protein correlates with disease-stage and chromosomal gain at the c-erbB2 locus in non-small cell lung cancer. Eur J Cancer 37: 1089-1095, 2001

40. Cragg MS, Kuroda J, Puthalakath H, Huang DC and Strasser A: Gefitinib-induced killing of NSCLC cell lines expressing mutant EGFR requires BIM and can be enhanced by BH3 mimetics. PLoS Med 4: 1681-1689, 2007. 
41. Kobayashi S, Boggon TJ, Dayaram T, Jänne PA, Kocher O, Meyerson M, Johnson BE, Eck MJ, Tenen DG and Halmos B: EGFR mutation and resistance of non-small-cell lung cancer to gefitinib. N Engl J Med 352: 786-792, 2005.

42. Fukuoka M, Yano S, Giaccone G, Tamura T, Nakagawa K, Douillard JY, Nishiwaki Y, Vansteenkiste J, Kudoh S, Rischin D, et al: Multi-institutional randomized phase II trial of gefitinib for previously treated patients with advanced non-small-cell lung cancer (The IDEAL 1 Trial). J Clin Oncol 21: 2237-2246, 2003

43. Tang JM, He QY, Guo RX and Chang XJ: Phosphorylated Akt overexpression and loss of PTEN expression in non-small cel lung cancer confers poor prognosis. Lung Cancer 51: 181-191, 2006.

44. Tsurutani J, Fukuoka J, Tsurutani H, Shih JH, Hewitt SM, Travis WD, Jen $\mathbf{J}$ and Dennis PA: Evaluation of two phosphorylation sites improves the prognostic significance of Akt activation in non-small-cell lung cancer tumors. J Clin Oncol 24: 306-314, 2006.

45. Tsao AS, McDonnell T, Lam S, Putnam JB, Bekele N, Hong WK Kurie JM: Increased phospho-AKT (Ser473) expression in bronchial dysplasia: Implications for lung cancer prevention studies. Cancer Epidemiol Biomarkers Prev 12: 660-664, 2003

46. Nakamura H, Fujita K, Nakagawa H, Kishi F, Takeuchi A, Aute I and Kato H: Expression pattern of the scaffold protein IQGAP1 in lung cancer. Oncol Rep 13: 427-431, 2005.

47. Lele L, Hailin P, Pei Q, et al: The effect of down regulation of IQGAP1 on the biological behavior of non-small cell lung cancer PC14/B

48. Gao J, McConnell MJ, Yu B, Li J, Balko JM, Black EP, Johnson JO, Lloyd MC, Altiok S and Haura EB: MUC1 is a downstream target of STAT3 and regulates lung cancer cell survival and invasion. Int J Oncol 35: 337-345, 2009.

49. Yin ZJ, Jin FG, Liu TG, Fu EQ, Xie YH and Sun RL: Overexpression of STAT3 potentiates growth, survival and radioresistance of non-small-cell lung cancer (NSCLC) cells J Surg Res 171: 675-683, 2011.

50. Jones FS and Jones PL: The tenascin family of ECM glycoproteins: Structure, function and regulation during embryonic development and tissue remodeling. Dev Dyn 218: 235-259, 2000

51. Dmitriev AA, Kashuba VI, Haraldson K, Senchenko VN, Pavlova TV, Kudryavtseva AV, Anedchenko EA, Krasnov GS Pronina IV, Loginov VI, et al: Genetic and epigenetic analysis of non-small cell lung cancer with NotI-microarrays. Epigenetics 7: 502-513, 2012.
52. Anedchenko EA, Dmitriev AA, Krasnov GS, Kondrat'eva TT, Kopantsev EP, Vinogradova TV, Zinov'eva MV, Zborovskaia IB, Polotskiı BE, Sakharova OV, et al: Down-regulation of RBSP3/CTDSPL, NPRL2/G21, RASSF1A, ITGA9, HYAL1 and HYAL2 genes in non-small cell lung cancer. Mol Biol (Mosk) 42: 965-976, 2007 (In Russian).

53. Fan Z, LinLang G and XiangBin M: Analysis of integrins differential expression in lung cancer cells. Cancer Research on Prevention and Treatment 36: 734-736, 2009.

54. Hofmann HS, Bartling B, Simm A, Murray R, Aziz N, Hansen G, Silber RE and Burdach S: Identification and classification of differentially expressed genes in non-small cell lung cancer by expression profiling on a global human 59.620-element oligonucleotide array. Oncol Rep 16: 587-595, 2006.

55. Lu Y, Govindan R, Wang L, Liu PY, Goodgame B, Wen W, Sezhiyan A, Pfeifer J, Li YF, Hua X, et al: MicroRNA profiling and prediction of recurrence/relapse-free survival in stage I lung cancer. Carcinogenesis 33: 1046-1054, 2012.

56. Kim YI, Lee A, Lee BH and Kim SY: Prognostic significance of syndecan-1 expression in cervical cancers. J Gynecol Oncol 22: 161-167, 2011.

57. Januchowski R, Zawierucha P, Ruciński M, Nowicki M and Zabel M: Extracellular matrix proteins expression profiling in chemoresistant variants of the A2780 ovarian cancer cell line. Biomed Res Int: 365867, 2014.

58. Anton ES, Hadjiargyrou M, Patterson PH and Matthew WD: CD9 plays a role in Schwann cell migration in vitro. J Neurosci 15: 584-595, 1995.

59. Ono M, Handa K, Withers DA and Hakomori S: Motility inhibition and apoptosis are induced by metastasis-suppressing gene product CD82 and its analogue CD9, with concurrent glycosylation. Cancer Res 59: 2335-2339, 1999.

60. Zhu R, Xu R, Jiang X, Cai Y, Zou Y, Du M and Qin L: Expression profile of cancer-related genes in human adult bone marrow-derived neural stemlike cells highlights the need for tumorigenicity study. J Neurosci Res 85: 3064-3070, 2007.

61. Aravalli RN, Talbot NC and Steer CJ: Gene expression profiling of MYC-driven tumor signatures in porcine liver stem cells by transcriptome sequencing. World J Gastroenterol 21: 2011-2029, 2015.

62. Nwariaku F, Sikes P, Lightfoot E, McIntyre K and Mileski WJ: Role of CD14 in hemorrhagic shock-induced alterations of the monocyte tumor necrosis factor response to endotoxin. J Trauma 40: 564-567, 1996.

63. Madjd Z, Durrant LG, Bradley R, Spendlove I, Ellis IO and Pinder SE: Loss of CD55 is associated with aggressive breast tumors. Clin Cancer Res 10: 2797-2803, 2004. 